\title{
DETERMINING SAFETY STOCKS IN THE PRESENCE OF WORKLOAD-DEPENDENT LEAD TIMES
}

\author{
Seza Orcun \\ e-Enterprise Center at Discovery \\ Park \\ Purdue University \\ West Lafayette, IN 47907, U.S.A. \\ Sıla Çetinkaya \\ Industrial and Systems Engineering \\ Department \\ Texas A\&M University \\ College Station, TX 77843-3131, U.S.A.
}

\author{
Reha Uzsoy \\ Laboratory for Extended Enter- \\ prises at Purdue \\ School of Industrial Engineering \\ Purdue University \\ West Lafayette, IN 47907, U.S.A.
}

\begin{abstract}
Most classical stochastic inventory models assume that replenishment lead times are independent of the amount of orders placed. This assumption is clearly problematic in capacitated production systems, where queueing models show that mean cycle time is a nonlinear increasing function of resource utilization. We use a simulation environment created for rapid prototyping of supply chains to examine the problem of setting safety stocks in environments with workload-dependent lead times. We show that even when extensive historical data is used, conventional approaches to setting safety stocks fail to provide the desired service level when lead times are load-dependent, and suggest directions for future research.
\end{abstract}

\section{INTRODUCTION}

An extensive body of literature on stochastic models of inventory systems has developed since the 1960s (Hadley and Whitin (1963); Zipkin (1997)). The vast majority of these models has emphasized the stochastic nature of demand, using relatively simple models of the replenishment process. Specifically, most models either assume a constant replenishment lead time, or a time-stationary lead time distribution. In both cases, the replenishment lead time is independent of the quantity ordered.

While these models may be defensible in distribution environments, where the replenishment process involves a supplier delivering material from a warehouse, it is problematic when the replenishment process involves a capacitated production system. It is well known from queueing models of production systems (Buzacott and Shanthikumar (1993); Hopp and Spearman (2001)) that the expected time in system, or cycle time, of a capacitated production system is a nonlinear increasing function of the resource utilization, which, in turn, is determined by the production control policy used to determine the timing of work release into the system. This latter body of research suggests that especially at high utilization levels, the assumption that cycle times are independent of the quantity ordered, i.e., the quantity of material released into the system, is not valid. However, the issue is of considerable practical importance, since many practitioners are faced with the problem of determining safety stock levels to support a specified customer service level for an inventory that is replenished from a production system.

In this paper we use the SCOPE simulation environment developed for rapid evaluation of supply chain configurations Orcun et al. (forthcoming) to illustrate this issue on a simple single-stage production-inventory system. We first assume a make to order environment, where demand is released directly to a supplier, who must manufacture the items demanded on a capacitated production line. We then examine the behavior of make to stock systems with different levels of safety stock, which are set using standard techniques from the literature developed under the assumption of time-stationary replenishment lead times. Our results suggest that the problem of determining the level of safety stock required to maintain a specified service level for this system is difficult, and that use of the standard techniques, even with access to very extensive historical data, does not consistently maintain specified service levels.

In the following section we provide a review of previous related work. Section 3 gives a brief description of the SCOPE environment in which the simulation models are implemented. Section 4 describes the different inventory systems simulated, and Section 5 presents the results of our experiments. We conclude the paper with a summary and suggestions for future research.

\section{PREVIOUS RELATED WORK}

The problem of managing production-inventory systems in the face of time-varying and uncertain demand has been addressed extensively by operations researchers over the last five decades. The literature in this area can be broadly 


\section{Orcun, Çetinkaya and Uzsoy}

classified into three main streams: optimization models of production planning, queueing models and stochastic inventory models.

\subsection{Production Planning Models}

The objective of production planning models is to allocate production capacity among different products over time in order to optimize some objective function, most commonly the sum of variable production, inventory holding and backorder costs over a finite planning horizon. These models have generally approached the problem as a deterministic optimization problem, where stochastic quantities are represented by deterministic estimates. This body of work has led to a wide range of linear and integer programming models (Hackman and Leachman (1989); Johnson and Montgomery (1974)), as well as the widely used Material Requirements Planning (MRP) approach (Vollmann et al. (2005)). However, the vast majority of these models treat lead times as exogeneous parameters, ignoring the relationship between workload and lead times. In recent years researchers have been developing enhanced models that comprehend workload-dependent lead times (Pahl et al. (2005)). Among these approaches, the use of clearing functions (Asmundsson et al. (2006b); Karmarkar (1989)), which relate the expected output of a production resource in a planning period to the expected WIP level over the period, have been promising; we will use this approach in the simulation models in this paper.

The most common treatment of safety stocks in this environment appears to be an offline analysis that arrives at inventory targets, which are then input into the production planning model as constraints. Meal (1979) and Miller

(1979), among others, discuss the issues related to safety stocks in an MRP environment. Another stream of work has been the use of optimization formulations with chance constraints (Charnes and Cooper (1959); Johnson and Montgomery (1974); Kempf and Uzsoy (2007)), which also appears promising. However, since the amount of safety stock needed will vary with the lead time, which in turn varies dynamically over the planning horizon with the release decisions, this area continues to be a challenging domain for research.

\subsection{Stochastic Inventory Models}

There is a very extensive literature on both deterministic and stochastic inventory models (Hadley and Whitin (1963); Zipkin (1997)). The majority of these models focus heavily on the stochastic nature of demand, and use simple models of the replenishment process. Very few of these models consider limited production capacity, and those that do generally assume workload-independent lead times. In recent years, however, a number of authors have examined the problem of setting safety stocks in inventory systems replenished from a capacitated production facility. Zipkin (1986) links a queuing model with an inventory model to examine the effects of lot-sizing on inventory levels in a single-stage production-inventory system. This work is further extended by Liu et al. (2004).

A different approach is followed by Graves and his coauthors (Graves (1988); Graves (1998)). This work postulates a linear relationship between inputs to the production system and outputs, either by having output be a fraction of the WIP level in a given period (Graves (1988)), or by having the planned output be a linear function of the forecast errors over a planning horizon (Graves (1998)). The approach in these papers is to characterize the distribution of the finished goods inventory level, and set a safety stock level accordingly. However, when the relationship between workload and lead times is nonlinear, this approach appears to become difficult due to the multiple correlations between the release pattern, WIP level and output of the system.

\subsection{Queueing Models}

The extensive literature on queueing models of manufacturing systems (Buzacott and Shanthikumar (1993); Hopp and Spearman (2001)) differs from the previous streams of research in that the nonlinear relationship between workload, expressed as average resource utilization, and expected cycle time, is widely recognized. However, the majority of this work is descriptive in nature, focusing on the characterization of long-run steady-state expected performance measures, which limit its direct applicability to practical problems.

\subsection{Summary}

It is apparent from this discussion that the tools provided by current research each address a particular aspect of the problem of setting safety stocks in capacitated productioninventory systems. The deterministic planning models generally fail to consider both the stochastic nature of demand and the workload-dependent nature of lead times, although some recent work is beginning to address these issues. Stochastic inventory models focus on long-run expected performance, and generally do not consider workloaddependent lead times. Queueing models capture the workload dependent nature of lead times correctly, but their long-run steady-state nature does not lend itself to planning safety stocks in the short term. Finally, there is a complex feedback relationship between safety stocks and lead times. It is well recognized that the amount of safety stock required in an inventory system with a significant lead time depends on the distribution of the demand over the lead time. However, in order to produce the material needed to provide the safety stock, additional releases are required, 


\section{Orcun, Çetinkaya and Uzsoy}

which, in turn, increases resource utilization and hence lead times. Thus it would appear that in order to be useful to practitioners, a decision support tool would have to integrate resource allocation in the presence of workloaddependent lead times with explicit recognition of the stochastic nature of demand and the need to maintain service levels. Kempf and Uzsoy (2007) propose a model that addresses these issues, but future research that extends the classical formulations in the literature is clearly needed in this area.

\section{SYSTEM UNDER STUDY}

The objective of this paper is limited in scope: we wish to illustrate the difficulty encountered using the classical inventory models to set safety stocks when lead times are workload-dependent, even when no production planning of any kind is done. To this end, we consider the simple twostage supply chain shown in Figure 1, where a retailer receives orders from customers, and places orders with a supplier. The supplier produces the items to order, and must ship complete orders to the retailer; hence, if the supplier does not have sufficient material in its finished goods inventory to meet the entire demand from the retailer, it will hold the entire order until enough material is available to ship the entire demand. The supplier has a capacitated production facility whose behavior is represented by a concave clearing function of the type used by Asmundsson et al. (2006b) and discussed in Orcun et al. (2006).

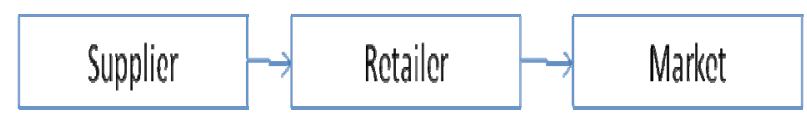

Figure 1: Simple 2-stage supply chain studied

Specifically, we derive the clearing function as follows: In order to represent the entire supplier facility using a single clearing function, we follow an approach similar in spirit to the Practical Worst Case analysis of Hopp and Spearman (2001). We assume that the average cycle time of 90 shifts corresponds to a bottleneck utilization level of 0.90 . Since the supplier process requires many manufacturing steps, the shortest possible time in which material that is introduced can emerge as finished product is given by the raw process time ( $R P T)$, which represents the average time for a lot to pass through the empty facility as defined by Hopp and Spearman (2001). We assume that the average cycle time $(C T)$ will follow relationship of the form

$$
\mathrm{CT}=\mathrm{RPT}+\mathrm{u}_{\mathrm{d}}\left(\mathrm{WIP} / \mathrm{C}_{\mathrm{d}}\right)
$$

where RPT is the raw processing time, $u_{d}$ the desired average utilization, WIP the work-in-progress inventory level and $\mathrm{C}_{\mathrm{d}}$ the desired average capacity that is utilized. The desired capacity in our case is thus given by $0.90 \mathrm{C}$, where $C$ is the maximum theoretical (design) capacity of the facility. Then, by Little's Law, the average throughput rate of the facility per period is given by

$$
\mathrm{TH}=\mathrm{WIP} / \mathrm{CT}
$$

Substituting (1) in (2) we obtain

$$
\mathrm{TH}=\mathrm{WIP}\left(\mathrm{C}_{\mathrm{d}} / \mathrm{u}_{\mathrm{d}}\right) /\left[\left(\mathrm{C}_{\mathrm{d}} / \mathrm{u}_{\mathrm{d}}\right) \mathrm{RPT}+\mathrm{WIP}\right]
$$

where the term $\left(\mathrm{C}_{\mathrm{d}} / \mathrm{u}_{\mathrm{d}}\right)$ RPT represents the time required to clear fully utilized plant. Equation (3) generates the behavior shown in Figure 2 when $C_{d}, u_{d}$ and RPT are set to 1400 units, 0.90 and 0.6428 , respectively. Under these parameter values, the desired capacity utilization is reached when WIP is 8400 units. This leads to an average cycle time of $84 / 14=6$ at the desired utilization level of 0.90 .

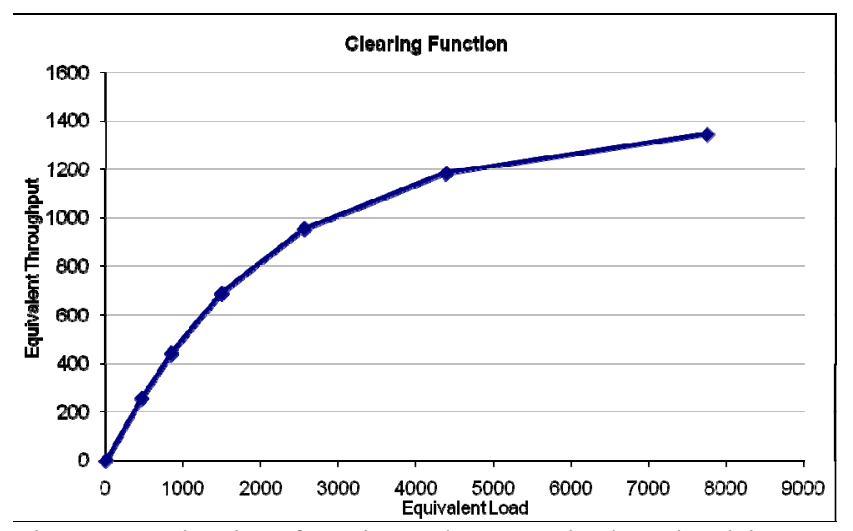

Figure 2: Clearing function where equivalent load is sum of equivalent throughput (which a function of equivalent work-in-progress) and equivalent work-in-progress

In most practical settings, a common approach is to establish a base stock level that assumes the distribution of the demand over the lead time to be normal. Let us denote the mean and standard deviation of the replenishment lead time by $\mu_{L}$ and $\sigma_{L}$, respectively, and let $\mu_{D}$ and $\sigma_{D}$ denote the mean and standard deviation of the demand per period. Then, the base stock level can be established as

$$
Y=\mu_{L} \mu_{D}+z_{\alpha} \sqrt{\mu_{L} \sigma_{D}^{2}+\sigma_{L}^{2} \mu_{D}^{2}}
$$

where $z_{\alpha}$ denotes the number of standard deviations required to provide a service level of $\alpha$, or, equivalently, a stock-out probability of 1- $\alpha$. (Eppen $1988 \# 109$ ) discuss the performance of this approach when demand over lead time violates the assumption of normality.

In order to establish a baseline (scenario 1), we first examine the behavior of the system where the supplier holds no safety stock at all, and operates in a pure make to order mode. Hence the pattern of work release into the supplier's production line represents the stream of demands from the market, passed through the retailer's order stream unaltered. We then examine three different scenarios $(2 \mathrm{a}, 2 \mathrm{~b}$ and $2 \mathrm{c})$ where the supplier sets safety stocks using the expression above. In the first of these, we use the entire history of the simulation results from the baseline 


\section{Orcun, Çetinkaya and Uzsoy}

scenario to estimate the mean and variance of the lead time used in setting the base stock level. Scenario $2 b$ uses the mean lead time from the historical data, but assumes the variance of lead time is zero. Last scenario (Scenario 2c) represents absence of historical data where mean lead time is set to its value at desired utilization, i.e. 6 , and neglects its variance as in scenario $2 b$.

\section{SIMULATION ENVIRONMENT AND COMPUTATIONAL EXPERIMENTATION}

The simulation studies of the scenarios are conducted using SCOPE environment. SCOPE views a supply chain as a directed graph whose nodes represent facilities such as manufacturing plants and distribution centers, while arcs represent both information and material flows. Information flows are divided into a backward information flow (backward pass) and forward information flow (commit pass) in addition to forward material flow (realization pass). The purpose of this distinction is to at least approximately represent the iterative negotiations/interactions that occur between elements of a supply chain.

During the backward pass, information flows from the market back up the supply chain towards the raw material suppliers, with each entity developing its production plans and placing orders with its suppliers. Once the information from the market has propagated upstream to the origin of the supply chain, the forward, or commit, pass is initiated. During the commit pass information flows from the raw material suppliers back towards the consumer, with each entity adapting its original plans to the amounts of inputs its suppliers are willing to provide. The realization pass updates the state of the system as it evolves in time, which may also capture realizations of process uncertainty within each node. This allows us to model many different situations where the realization of a system variable differs from that predicted by the models used to control the behavior of the system, such as the presence of random variables or the failure of planning models to accurately represent the behavior of the system.

This separation of forward and backward information flows provides the user significant flexibility in modeling information flows and modes of interaction between elements of the supply chain. During both forward and backward passes, time lags of different durations as well as different levels of information aggregation can be used to model different modes of interaction. The Commit Pass in particular allows the user to embed a wide variety of logic to determine how elements of the supply chain allocate their outputs among different customers, and how the effects of decisions by individual elements of the supply chain affect the rest of the system. The Backward Pass, on the other hand, provides considerable scope for modeling different degrees and forms of information sharing between elements of the supply chain. For example, the Col- laborative Forecasting, Planning and Replenishment (CFPR) approach advocated in the retail sector and studied extensively by several researchers can be implemented as a module invoked during the backward pass of a SCOPE run.

Further details on SCOPE environment can be found elsewhere (Orcun et al. (forthcoming)). Next section explains how the SCOPE environment has been set-up for computational experimentation of scenarios described in the previous section which is followed by discussion of the results of this experimental exploration.

\subsection{SCOPE Set-Up for Computational Experiments}

For the purpose of this experimental exploration the supply chain of Figure 1 is setup in the SCOPE environment. Retailer in all scenarios is a passive actor: retailer sees the demand (stationary and normally distributed with mean 1200 and variance $300^{2}$ ) at the market and passes it to the supplier instantaneously. The supplier releases new jobs equivalent to the demand it sees to its production facility. The production is governed by the clearing function given in Figure 2 which corresponds to realization pass of SCOPE environment. The supplier ships an order only if it can fulfill it completely obeying to first come first serve policy. For example the supplier will not be able to ship anything if the order in the line is 100 and the amount produced plus the finished goods inventory from last period is 99 even if an outstanding order of 80 is in the queue. At each period only one shipment which might fulfill more than one order is allowed between supplier and retailer. The retailer receives and relays the shipments instantaneously. Scenario 1, base case, carries zero safety stock, i.e. empty finished goods inventory but starts with steady state WIP (3400 determined from equation 3: $1200=$ WIP $(1400 / 0.90) /[(1400 / 0.90) 0.6428+$ WIP] to meet the mean/expected demand). This base case simulation results (100 replications) is used to determine the average lead time and demand, and their standard deviations (see Table 1). The purpose of looking at the lead time distribution instead of alternative approaches such as average inventory is study the effect of non-symmetrical non-linearity introduced by the clearing function due to congestion.

Table 1: Lead-time and demand characteristics inferred from scenario 1 results and used in scenario $2 \mathrm{a}$ and scenario $2 \mathrm{~b}$.

\begin{tabular}{|c|c|c|}
\hline & Average & Standard Deviation \\
\hline Lead Time & 2.999257 & 0.470976 \\
\hline Demand & 1199.163 & 299.6311 \\
\hline
\end{tabular}

Using equation (4), i.e. Base Stock: $F G I+W I P=1200 * 3+300 * 3^{0.5}$, the base stock is determined and split between work-in-progress, WIP, and finished goods inventory, $F G I$, with $\mathrm{z}=1.96$ as given in Table 2. For scenarios $2 \mathrm{a}$ and $2 \mathrm{~b}$, WIP is calculated from the clearing 
function (equation 3: $1200=$ WIP $(1400 / 0.90)$ / $[(1400 / 0.90) 0.6428+$ WIP] $)$ such that the throughput will approximately be equal to the expected/mean demand. Scenario 2c sets WIP using the expected lead-time at the desired utilization assuming linear relationship (equation 2: $\mathrm{WIP}=6 * 1200$ where 6 is the expected lead time at desired utilization). Note that starting with empty production facility with FGI equals to base stock at the long run (at the steady state) will yield the WIP and FGI split of Table 2 where FGI and WIP are analogous to inventory-on-hand and inventory-on-order, respectively.

Table 2: Base stock policy calculated for scenarios $2 \mathrm{a}, 2 \mathrm{~b}$ and $2 \mathrm{c}$ from scenario 1 simulation results.

\begin{tabular}{|c|c|c|c|}
\hline & $\begin{array}{c}\text { Base } \\
\text { Stock }\end{array}$ & WIP & FGI \\
\hline Scenario 2a & 5100 & 3400 & 1700 \\
\hline Scenario 2b & 4614 & 3400 & 1215 \\
\hline Scenario 2c & 8640 & 7200 & 1440 \\
\hline
\end{tabular}

Noting that the demand in the market is assumed stationary and releases to the production follows exactly the demand, the base stock policy is kept constant throughout the simulation (stationary base stock policy) to represent the current practices.

All the scenarios are simulated using the same demand stream of scenario 1 (common random numbers) to generate the results presented in the next section where work-inprogress cost, finished goods inventory cost and production cost are $1,0.6,8$ respectively. The simulations are hot started using the WIP and FGI of Table 2.

\subsection{Results and Discussions}

One direct observation from Table 1 is that the average observed lead-time at scenario 1 (2.99) is higher than the one calculated from equation (3) (2.81) to meet mean/expected demand.

As it can be noticed from Figure 3 as the safety stock increases (scenarios in the order of increasing safety stock: $2 \mathrm{~b}, 2 \mathrm{a}$ an $2 \mathrm{c}$ ) the customer service level improves. While scenario 1 performs worst (no safety stock), except for $2 \mathrm{c}$ none of the scenarios guarantee $95 \%$ customer service level.

Figure 4 further depicts the standard deviation of customer service level which follows similar trend to the average service level: The variation in customer service level is higher for poor customer service level.

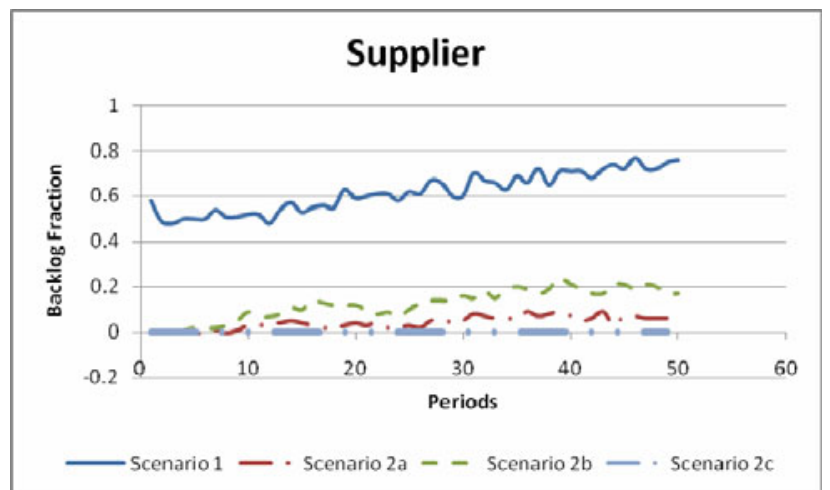

Figure 3: Average backlog fraction at the supplier

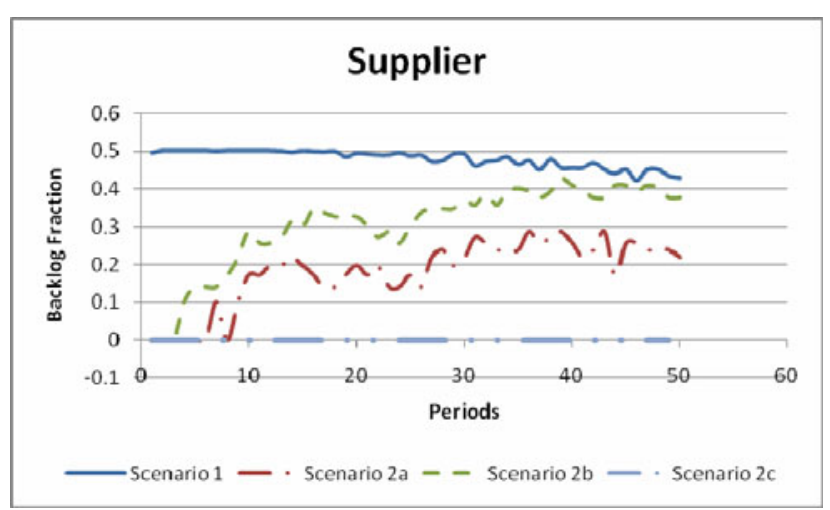

Figure 4: Standard deviation of backlog fraction at the supplier

Figures 5 and 6 point out that the higher customer service level comes with a high cost of finished goods inventory. No safety stock scenario (scenarios 1) have lowest finished goods inventory which is arising from backlogging without partial order fulfillment. The rising finished goods inventory (FGI) of scenario 2c reflects the extra WIP in the system (which was set using linear relationship equation 2 and using the expected lead-time at desired utilization) being transformed to FGI with time.

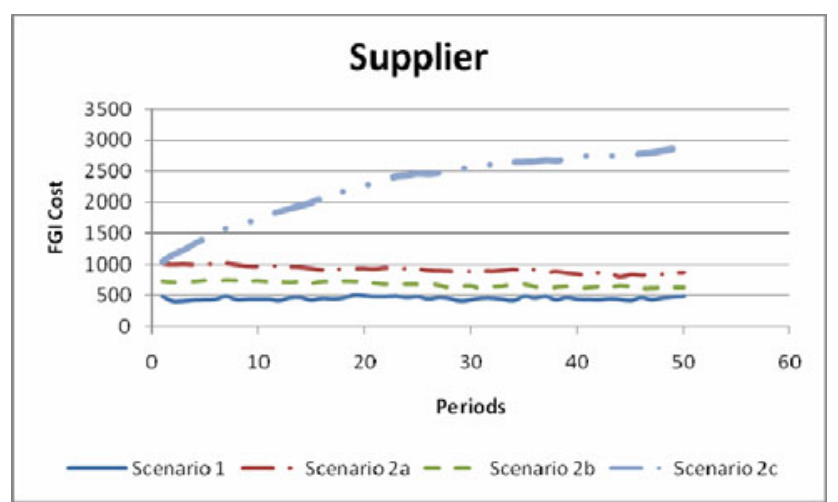

Figure 5: Average finished goods inventory cost at the supplier 


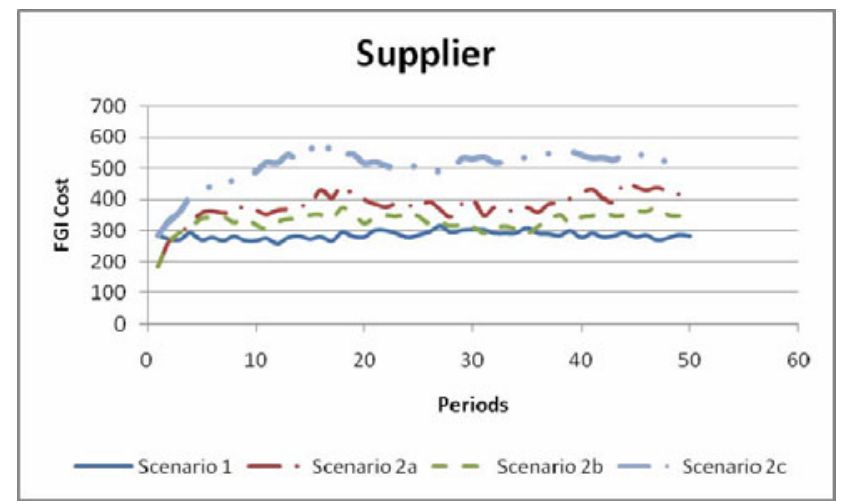

Figure 6: Standard deviation of finished goods inventory cost at the supplier

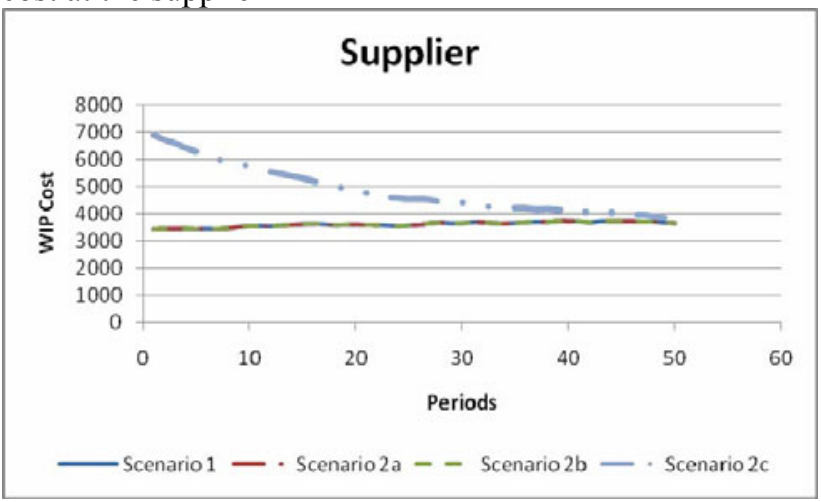

Figure 7: Average work-in-progress cost at the supplier

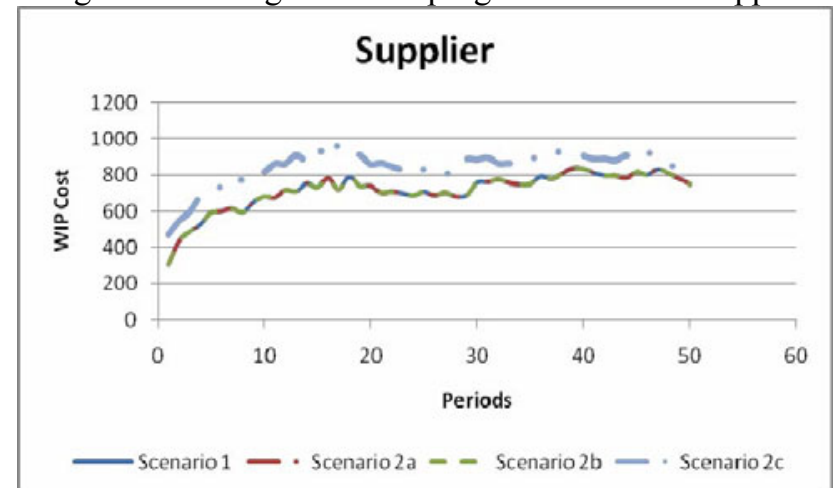

Figure 8: Standard deviation of work-in-progress cost at the supplier

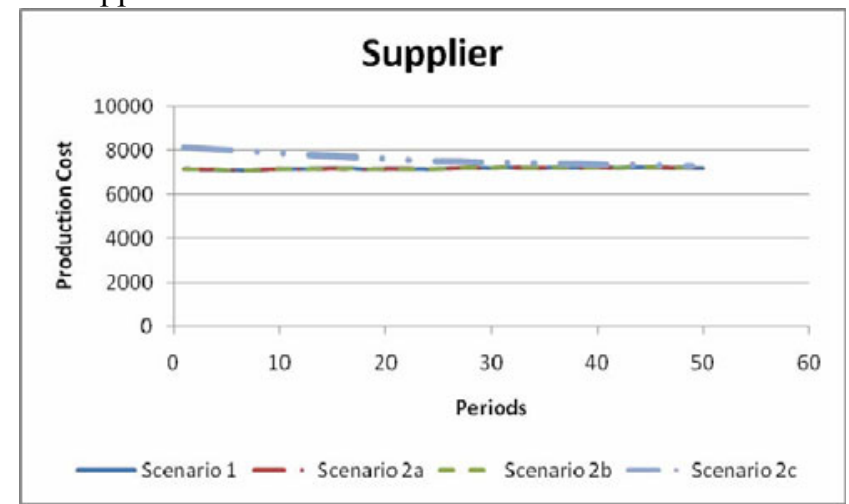

Figure 9: Average production cost at the supplier

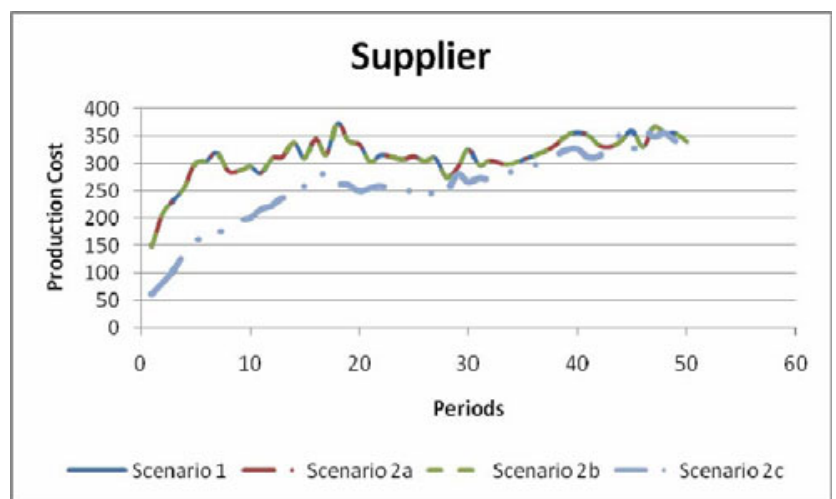

Figure 10: Standard deviation of production cost at the supplier

An interesting observation from Figure 6 is the increase in the variability of finished goods inventory as safety stock increases.

Figures 7 and 8 suggest that scenarios 1, 2a, 2b and 2c follow a stable work in progress profile which is not surprising since releases follow the demand profile.

Figures 9 and 10 follow the throughput pattern which is smooth for all of the scenarios which is a classic characteristic of congestions.

Table 3: Total costs of scenarios.

\begin{tabular}{|c|c|c|}
\hline & Total Cost & $\begin{array}{c}\text { Incremental Cost } \\
\text { (relative to Base Case) }\end{array}$ \\
\hline Scenario 1 & $1,083,152$ & - \\
\hline Scenario 2a & $1,107,031$ & 23,879 \\
\hline Scenario 2b & $1,094,479$ & 11,327 \\
\hline Scenario 2c & $1,264,430$ & 181,278 \\
\hline
\end{tabular}

Table 4: Average backlog fractions of scenarios.

\begin{tabular}{|c|c|c|}
\hline & $\begin{array}{c}\text { Average } \\
\text { Backlog } \\
\text { Fraction }\end{array}$ & $\begin{array}{c}\text { Incremental } \\
\text { Improvement } \\
\text { (relative to Base Case) }\end{array}$ \\
\hline Scenario 1 & 0.6219 & - \\
\hline Scenario 2a & 0.0415 & 0.5804 \\
\hline Scenario 2b & 0.1267 & 0.4952 \\
\hline Scenario 2c & 0.0000 & 0.6219 \\
\hline
\end{tabular}

Table 5: Costs of unit improvement of customer service level relative to base case (incremental cost divided by incremental improvement).

\begin{tabular}{|c|c|}
\hline & Cost \\
\hline Scenario 1 & - \\
\hline Scenario 2a & 41,143 \\
\hline Scenario 2b & 22,874 \\
\hline Scenario 2c & 291,480 \\
\hline
\end{tabular}

Tables 3-5 summarize the total cost, average customer service level and cost of unit improvement from base case (scenario 1) of each scenario compared to base case, respectively. As expected the total cost increases as base 


\section{Orcun, Çetinkaya and Uzsoy}

stock increases. Scenario $2 \mathrm{c}$ depicts the consequence of over loading the system especially when lead-time depends on utilization.

\section{CONCLUSIONS}

In this work we presented how the commonly used approaches to set safety stocks behave when the production is governed by load dependent lead time, represented by clearing function. The main conclusion we can drive from the results is that due to non-linear dependence of leadtime to utilization, throughput no longer follows the demand stream's independently identically distributed characteristic and hence the safety stock does not guarantee the customer satisfaction level set in the equation (4). Another interesting conclusion is that though Scenario $2 \mathrm{~b}$ does not perform as well as scenario $2 \mathrm{a}$ the cost of unit improvement in customer satisfaction is lower than scenario $2 \mathrm{a}$ which indicates diminishing rate of return. Scenario $2 \mathrm{c}$ highlights the fact that it is not cheap to hedge the demand variability with work-in-progress inventory.

One natural extension of this work is exploring how to set-up optimal base stock policy when the production is governed by non-linear operating curve, e.g. clearing function. More interestingly, this study suggests that effect of planning models, which account for non-linear dependence between lead-time and utilization, on optimal base stock policy might be more pronounced as they distort the release pattern away from the demand stream by smoothing the production under high utilization.

\section{ACKNOWLEDGMENTS}

The research of Reha Uzsoy and Seza Orcun was supported by a grant from the Intel Research Council.

\section{REFERENCES}

Asmundsson, J. M., R. L. Rardin and R. Uzsoy (2006b). "Tractable Nonlinear Production Planning Models for Semiconductor Wafer Fabrication Facilities." IEEE Transactions on Semiconductor Manufacturing 19: 95-111.

Buzacott, J. A. and J. G. Shanthikumar (1993). Stochastic Models of Manufacturing Systems. Englewood Cliffs, NJ, Prentice-Hall.

Charnes, A. and W. W. Cooper (1959). "ChanceConstrained Programming." Management Science 6(1): 73-79.

Eppen, G. and R. K. Martin (1988). "Determining Safety Stock in the Presence of Stochastic Lead Times." Management Science 34: 1380-1390.

Graves, S. C. (1988). "Safety Stocks in Manufacturing Systems." Journal of Manufacturing and Operations Management 1: 67-101.
Graves, S. C. (1998). "A Dynamic Model for Requirements Planning with Application to Supply Chain Optimization." Operations Research 46(Supp. No. 3):S35-S49.

Hackman, S. T. and R. C. Leachman (1989). "A General Framework for Modeling Production." Management Science 35: 478-495.

Hadley, G. and T. M. Whitin (1963). Analysis of Inventory Systems. Englewood Cliffs, NJ, Prentice-Hall. Hopp, W. and M. L. Spearman (2001). Factory Physics. Boston, Irwin.

Johnson, L. A. and D. C. Montgomery (1974). Operations Research in Production Planning, Scheduling and Inventory Control. New York, John Wiley.

Karmarkar, U. S. (1989). "Capacity Loading and Release Planning with Work-in-Progress (WIP) and Leadtimes." Journal of Manufacturing and Operations Management 2(105-123).

Kempf, K. G. and R. Uzsoy (2007). Integrating Workload Dependent Lead Times and Safety Stocks into Mathematical Programming Models for Production Planning. Research Report, Laboratory for Extended Enterprises, School of Industrial Engineering, Purdue University. West Lafayette, IN.

Liu, L., X. Liu and D. D. Yao (2004). "Analysis and Optimization of Multi-stage Inventory Queues." Management Science 50: 365-380.

Meal, H. (1979). Safety Stocks in MRP Systems. Operations Research Center, Massachusetts Institute of Technology. Cambridge, MA.

Miller, J. G. (1979). Hedging The Master Schedule. Disagregation Problems in Manufacturing and Service Organizations. L. P. Ritzman. Boston, MA, Martinus Nijhoff.

Orcun, S., J. M. Asmundsson, J. F. Pekny, R. L. Rardin and R. Uzsoy (forthcoming). "Supply Chain Optimization and Protocol Environment (SCOPE) for Rapid Prototyping of Supply Chains." Production Planning and Control.

Orcun, S., R. Uzsoy and K. G. Kempf (2006). Using System Dynamics Simulations to Compare Capacity Models for Production Planning. Winter Simulation Conference. Monterey, CA.

Pahl, J., S. Voss and D. L. Woodruff (2005). "Production Planning with Load Dependent Lead Times." 4OR: A Quarterly Journal of Operations Research 3: 257-302.

Vollmann, T. E., W. L. Berry, D. C. Whybark and F. R. Jacobs (2005). Manufacturing Planning and Control for Supply Chain Management. . New York, McGrawHill.

Zipkin, P. H. (1986). "Models for Design and Control of Stochastic, Multi-Item Batch Production Systems." Operations Research 34(1): 91-104.

Zipkin, P. H. (1997). Foundations of Inventory Management. Burr Ridge, IL, Irwin. 


\section{Orcun, Çetinkaya and Uzsoy}

\section{AUTHOR BIOGRAPHIES}

SEZA ORCUN is an associate research scientist at the eEnterprise Center at Discovery Park of Purdue University. He has completed BS (1994), MS (1995) and Ph.D. (1999) programs in Chemical Engineering at Bogazici University, Istanbul-Turkey. He joined to Purdue University as a postdoctoral research associate in early 1999 and promoted to a fulltime research associate appointment in early 2002 in the School of Chemical Engineering before accepting his current appointment in mid 2004. His research in scheduling and planning of process industries focuses on developing novel and practically usable scheduling and planning tools/environments, which can be used in daily decision making as well as in training programs for industrial practices. His affiliation with Laboratory for Extended Enterprises at Purdue (LEEAP) expands his research area and vision to supply chain modeling, design and management. His e-mail address is $\langle$ sorcunepurdue.edu $\rangle$.

SILA ÇETINKAYA is an Associate Professor of Industrial and Systems Engineering at Texas A\&M. She received her BSIE (1989) and MSIE (1991) degrees in Turkey from Istanbul Technical University and Bilkent University, respectively. She holds a Ph.D. (1996) in Management Science from McMaster University in Canada. Her research interests include supply chain management, inventory theory, and applied probability. Çetinkaya's publications appeared in Management Science, Operations Research, Naval Research Logistics, IIE Transactions, and European Journal of Operational Research among other refereed journals. Her research and teaching activities have been supported by the National Science Foundation, Texas Engineering Education Coordination Board, US Department of Education, and Frito-Lay, Pepsi-Co, and Nokia among other companies. In 2001, she received the National Science Foundation CAREER Award. She was named the Outstanding Young Industrial Engineer by IIE in 2003, Texas Engineering Experiment Station Fellow in 2006, and Texas A\&M Dwight Look College of Engineering Faculty Fellow in 2003 and 2006. She was also awarded the BP Faculty Award for Teaching Excellence in 2004 and E.D. Brockett Professorship in 2006. She is a department editor for IIE Transactions, an area editor for Canadian Journal of Administrative Sciences, an associate editor for Naval Research Logistics, and a member of the editorial board of International Journal of Inventory Research. Her e-mail address is $<$ sila@tamu. edu $>$.

REHA UZSOY is a Professor in the School of Industrial Engineering and Director of the Laboratory for Extended Enterprises at Purdue University. He holds BS degrees in Industrial Engineering and Mathematics and an MS in Industrial Engineering from Bogazici University, Istanbul, Turkey. He received his Ph.D in 1990 from the University of Florida and joined the faculty of Purdue University the same year. His teaching and research interests are in production planning, scheduling, and supply chain management. He is the author of one book, an edited book, and over sixty refereed journal publications. Before coming to the US he worked as a production engineer with Arcelik AS, a major appliance manufacturer in Istanbul, Turkey. $\mathrm{He}$ has also worked as a visiting researcher at Intel Corporation and IC Delco. His research has been supported by the National Science Foundation, Intel Corporation, Hitachi Semiconductor, Harris Corporation, Kimberly Clark, Union Pacific and General Motors. He was named a Fellow of the Institute of Industrial Engineers in 2005, Outstanding Young Industrial Engineer in Education by the Institute of Industrial Engineers in 1997 and a University Faculty Fellow by Purdue University in 2001, and has received both the A.A. B. Pritsker Award for Excellence in Undergraduate Teaching and the J. H. Greene Award for Outstanding Graduate Instructor (twice). He is currently serving on the Editorial Boards on IIE Transactions on Scheduling and Logistics and Journal of Manufacturing Systems. His e-mail address is <uzsoyepurdue.edu> 